\title{
TSUNAMI EVACUATION SIMULATION WITH MULTI-AGENTS AND DECISION MAKING ON A COUNTERMEASURE WITH AHP
}

\begin{abstract}
We propose an integration method that uses the analytic hierarchy process (AHP) and agent-based modeling to simulate tsunami evacuation and to make decision on a countermeasure. First, we create multiagent coast models that include a tsunami agent, shelter agents, road agents and evacuee agents. We then estimate the evacuation success/failure number by using a computer simulation based on multiagent coast models. Finally, we use AHP to determine the countermeasure against tsunami disaster.
\end{abstract}

Keywords: agent-based modeling, tsunami disaster, countermeasure decision making.

\section{Introduction}

Multiagent-based social simulations have been extensively investigated, and various attempts have been made to apply them to the layout design of supermarkets (Yamane et al. 2012), stock markets (Panayi et al. 2012), sales prediction (Kohara et al. 2014) and tsunami evacuation (e.g., (Saito et al. 2005)). We investigated the real-world problem of predicting the tsunami evacuation success/ failure number and using that prediction to determine the countermeasure against tsunami disaster. We propose an integrated method that uses the analytic hierarchy process (AHP) and agent-based modeling to predict the evacuation success/failure number and determine the countermeasure. First, we created multiagent coast models that consist of a tsunami agent, shelter agents, road agents and evacuee agents. Then, we estimated the predicted evacuation success/failure number by using a computer simulation with multiagent coast models. Finally, we used AHP to decide the countermeasure against tsunami disaster. The main features of our method are as follows: (1) we introduce tsunami into the coast models as an agent; (2) we divide the coast into several districts, predict the tsunami evacuation success/failure number of each district and consider several countermeasures (adding a shelter, adding an evacuation route) using that prediction; (3) we estimate effects of each countermeasure; (4) we determine the countermeasure using the results of multiagent simulation and AHP.

\section{Multiagent Coast Models}

We created a multiagent coast model based on a popular coast in Shizuoka Prefecture. The width of the coast is $2 \mathrm{~km}$. Since the size of the coast model is 100 cells by 200 cells, one cell corresponds to $10 \mathrm{~m}$ in each direction. Evacuees move one cell per step. Evacuees move $100 \mathrm{~m}$ per minute, so a minute corresponds to 10 steps. Evacuees move one cell per two steps at a sloping road. Tsunami moves two cells per step. Here, we assumed that (1) 10 meter high tsunami arrives at 10 minutes after the earthquake, (2) $60 \%$ of evacuees start to evacuate immediately, $30 \%$ of evacuees start at 5 minutes after the earthquake, and $10 \%$ of evacuees start at the time of arrival of the tsunami, based on questionnaire results. There are four kinds of agents: a tsunami agent, shelter agents, road 
ISAHP Article: A Style Guide for Paper Proposals To Be Submitted to the International Symposium on the Analytic Hierarchy Process 2016, London, U.K.

agents and evacuee agents. Number of evacuee agents is 3000, based on the published number of bathing people at the coast. Number of shelters is 10 , based on the real information. Evacuee agents move to higher direction. When evacuees arrive at the intersection, they move according to traffic signs. If there is a shelter, they go to the shelter. Otherwise, they move to higher direction.

\section{Predicting Evacuation Success/Failure Number}

First, we divided the coast into five districts (A, B, C, D and E). We generated 600 people in each district and estimated the evacuation success number of each district. The results are as follows: 472 for A, 475 for B, 452 for C, 480 for D, and 483 for E. Second, we generated 3000 people in the coast and estimated the evacuation success number. The average number of 50 trials was 2473. Third, we added a shelter (shelter $\mathrm{K}$ at district B, shelter $\mathrm{L}$ at district $\mathrm{C}$, or shelter $\mathrm{M}$ at district $\mathrm{D}$ ) or an evacuation route (route $\mathrm{X}$ at district $\mathrm{A}$, route $\mathrm{Y}$ at district $\mathrm{B}$, or route $\mathrm{Z}$ at district $\mathrm{C}$ ) based on the above results and the real map. The average failure number of 50 trials was 449 for adding shelter K, 372 for L, 343 for M, 236 for adding route $\mathrm{X}, 230$ for $\mathrm{Y}$ and 164 for $\mathrm{Z}$.

\section{Determining a Countermeasure by Using AHP}

Here, we used the following four criteria: feasibility, evacuation success rate, cost, and time required to realize the countermeasure. Here, we used the following four alternatives: (1) adding shelter L, (2) adding shelter M, (3) adding evacuation route Y, and (4) adding evacuation route $\mathrm{Z}$. We evaluated the pairwise comparison matrices for the four criteria in three cases. Our final results are as follows: adding evacuation route $\mathrm{Z}$ is best (0.317) when feasibility and evacuation success rate are equally most important, adding shelter $\mathrm{M}$ is best (0.389) when cost is most important, and adding evacuation route $\mathrm{Z}$ is best (0.394) when required time is most important.

\section{Conclusion}

We propose integrating the AHP with agent-based modeling for predicting tsunami evacuation success/failure number and making decisions about countermeasure against tsunami disaster. First, we created multiagent coast models. Second, we divided the coast into five districts and estimated the evacuation success number. Third, we added a shelter or an evacuation route and estimated the failure number. Finally, we applied the AHP with four criteria. We applied our method to an actual coast and showed its effectiveness.

\section{References}

Kohara, K., \& Sekigawa, D. (2014). Sales prediction with multiagent town models and deciding stores location with AHP. ISAHP 2014.

Panayi, E., et al. (2012). Agent-based modeling of stock markets using existing order book data. MABS'12 (13th International Workshop on Multi-Agent Based Simulation).

Saito T., \& Kagami H. (2005). Simulation of evacuation behavior from tsunami utilizing multiagent system. J. Archit. Plann., AIJ, No.597, 229-234.

Yamane, S., et al. (2012). Agent-based social simulation for a checkout layout design of a specific supermarket. MABS'12. 